\title{
Why Science Communication, and Does It Work? A Taxonomy of Science Communication Aims and a Survey of the Empirical Evidence
}

\author{
Klemens Kappel ${ }^{1 *}$ and Sebastian Jon Holmen ${ }^{2}$ \\ ${ }^{1}$ Department of Philosophy, University of Copenhagen, Copenhagen, Denmark, ${ }^{2}$ Department of Philosophy and Science \\ Studies, Roskilde University, Roskilde, Denmark
}

OPEN ACCESS

Edited by:

Carrie Figdor

The University of lowa, United States

Reviewed by:

Ann Grand,

University of Exeter, United Kingdom

Scott Aikin

Vanderbilt University, United States

*Correspondence:

Klemens Kappel

kappe/@hum.ku.dk

Specialty section: This article was submitted to

Science and Environmental

Communication,

a section of the journal

Frontiers in Communication

Received: 02 July 2019 Accepted: 08 October 2019

Published: 25 October 2019

Citation: Kappel K and Holmen SJ (2019) Why Science Communication, and Does it

Work? A Taxonomy of Science Communication Aims and a Survey of the Empirical Evidence.

Front. Commun. 4:55

doi: 10.3389/fcomm.2019.00055
In this paper, we offer a novel conceptual framework of some of the most important aims for science communication efforts found in the contemporary literature on science communication. We identify several distinct aims present in the literature such as generating public epistemic and moral trust, generating social acceptance, and enhancing democratic legitimacy, and we discuss some of the relations between the different aims. Finally, we examine whether and, if so, to what extent these different aims can be said to have been successfully reached in practice and find that the empirical literature regarding the evaluation of science communications efforts is scarce. We conclude by suggesting that science communicators be attentive to formulating their communicative aim(s) in more precise terms, as well as conduct systematic studies of the effectiveness of their communicative efforts.

Keywords: science communication, democratic legitimacy, trust, consensus conference, science literacy, Citizen Science projects

\section{INTRODUCTION}

Although there seems to be a discrepancy between which aims they highlight in their analysis, there appear to be a growing interest among scholars in identifying and analyzing the aims of science communications efforts. For instance, Burns et al. (2003) included five such aims as part of their influential definition of science communication (i.e., increased awareness, enjoyment, interest, opinion-forming, and understanding) and discussed some of the relations between them. SánchezMora (2016) has proposed that communicating "[...] that science exists, feeling that science is attractive, understanding that it is interesting, or being aware that science is part of one's identity." (p. 2) are the four major objectives of public communication of science. And in a recent report by The National Academies of Sciences, Engineering and Medicine the five general goals for science communication were identified as (i) sharing recent findings and excitement for science, (ii) increasing public appreciation of science, (iii) increasing knowledge and understanding of science, (iv) influencing the opinions, policy preferences or behavior of people, and (v) ensuring that a diversity of perspectives about science held by different groups are considered when solutions to societal problems are pursued (National Academies of Sciences, Engineering, and Medicine, 2017). However, while attention is thus being paid to the aims of science communication, the current literature scrutinizing said aims seems to have several important limitations. First, the analyses of the aims are not sufficiently fine-grained, and several aims therefore remain implicit and unarticulated. Second, the aims that have been identified by scholars are often undertheorized in the sense that they are not specified in philosophically precise terms. Third, and in part 
as a consequence of the other limitations, the relations and interaction between aims remain underexplored. As an initial step toward amending these shortcomings, we propose a conceptual framework for explicating some of the most important aim(s) of science communications efforts observed in the contemporary science communication literature, a framework that draws on standard concepts from epistemology and political philosophy. This approach carries the advantage of providing a more fine-grained and analytically rich way of distinguishing the underlying aims of different communicative efforts than has hitherto been offered. We identify eight conceptually distinct aims often explicitly or implicitly advocated in the literature, discuss possible or likely causal connections between them and discuss how they might be conflicting. Finally, we examine the empirical literature to assess to what extent evidence exists that the various aims have been successfully reached by communicative efforts in practice.

\section{TWO PARADIGMS OF SCIENCE COMMUNICATION}

At a general level there seems to be agreement in the literature that models for science communication can be divided into two paradigms. Some models view one-way transmission of information about science from experts to the public as the appropriate way to communicate science. Other models in contrast view dialogue and deliberation between the public, experts and decision-makers as the proper way of engaging in science communication (for a similar distinction, see Bauer et al., 2007; Trench, 2008; Brossard and Lewenstein, 2010; Akin and Scheufele, 2017). We shall refer to the former cluster of models as the dissemination paradigm and we shall term the latter the public participation paradigm. One important way that the paradigms differ is by emphasizing different aims for science communication. Another key point of divergence lies in the methods or outlets that the paradigms recommends. We shall mostly focus our attention on the former point of divergence in sections A Conceptual Framework of Science Communication Aims and Do Various Models of Science Communication Achieve the Aims? In this section, we shall attempt to answer the question of what methods the models belonging to the dissemination paradigm and the public participation paradigm propose as means to communicate science.

\section{The Dissemination Paradigm of Science Communication}

As noted above models belonging to the dissemination paradigm see science communication as a matter of (successfully) transmitting information about science from scientific experts to the public. The most prominent views assume that the transmission is to be effectuated through education in a formal school setting or (re)education through mass media (The Royal Society, 1985; Ziman, 1991; Bauer et al., 2007). The implications of the focus on formal education includes the initiation in many countries of extensive revisions of national science curricula (Turner, 2008; Brossard and Lewenstein, 2010) as well as a call for universities to take steps to encourage alumni to continue to be educated about science after they graduate (Miller, 2012). Implications of the focus on dissemination through the mass media include the production of popular science books, television documentaries, science magazines and, more recently, communication through science blogs and websites (Bubela et al., 2009; Gastil, 2017).

More recently, scholars have emphasized that the context that a particular person is in can affect his or her understanding and evaluation of science. Thus, some models belonging to the dissemination paradigm recognize the heterogeneity of multiple publics in society and the consequences that this may have on how people respond to communicative efforts. These models stress that, while linear transmission of information is still the preferred method of communication (see e.g., Nisbet, 2010; Druckman and Lupia, 2017), we should recognize that individuals "process information according to social and psychological schemas that have been shaped by their previous experiences, cultural context, and personal circumstances" (Brossard and Lewenstein, 2010, p. 14).

In a further development, scholars have recently started investigating how one might disseminate scientific information in such a way that it counteracts or circumvents some of the known problems with achieving effective science communication associated with the social and psychological make-up of different audiences. Humans have a tendency to employ cognitive heuristics, which in some cases lead to a biased selection and interpretation of information about science. This phenomenon has recently received much attention from scholars (see e.g., Kahan, 2010; Kahan et al., 2010; Nisbet, 2010; Druckman and Lupia, 2017). In the same vein, some work is exploring ways to harness our use of heuristics in ways that are conducive to successful communicative efforts (see e.g., Correll et al., 2004; Nisbet and Scheufele, 2009; Kaplan and Dahlstrom, 2017).

\section{The Public Participation Paradigm of Science Communication}

The focus for most models of science communication in the public participation paradigm is on facilitating two-way communication, that is, dialogue and (sometimes) deliberation between the public, experts and policy-makers (Gastil, 2017) ${ }^{1}$. Numerous ways of doing so have been suggested, ranging from familiar approaches such as public hearings and referendums (Rowe and Frewer, 2000), to the perhaps less familiar approaches such as Science Shops (Wachelder, 2003), Scenario Workshops

\footnotetext{
${ }^{1}$ One might object that science communication efforts that are dialogic in nature and those that are deliberative in nature differ sufficiently in their approach to participation so as to merit separate discussion. In our view, however, the difference between these two approaches to science communication is a matter of degree rather than kind. That is, both science communication efforts that employ dialogic tools and those that employ deliberative ones can be classified as being participatory, but the latter might be so to a greater degree than the former. For this reason, we categorize both approaches as belonging to the public participation paradigm of science communication.
} 
(Andersen and Jæger, 2001), Citizens Juries (Smith and Wales, 1999), Planning Cells (Hörning, 1999), Deliberative Polling (Fishkin et al., 2000; Fishkin, 2003), and many others (Gastil and Levine, 2005; Rowe and Frewer, 2005). In order to provide a clearer picture of how some of the models belonging to this paradigm are structured and how diverse they can be, we shall briefly review two paradigmatic examples of models licensed by this paradigm, namely Citizens Science and Consensus Conferences.

Citizen Science are projects that "enlists the public in collecting large quantities of data across an array of habitats and locations over long spans of time" (Bonney et al., 2009, p. 977). To put it differently, Citizen Science is, as the name indicates, science conducted by citizens ${ }^{2}$. Development and implementation of Citizens Science Projects are recommended to follow the following nine steps (see Bonney et al., 2009). First, the scientific question that one wish to have answered is formulated. Often this question will have a large spatial and/or temporal scope and is tailored in such a way that gathering the necessary observations can be done without having expert knowledge. Second, a team of experts are formed to oversee the project and process the data collected. Third, protocols, data forms and educational material is developed, tested, and refined. The fourth and fifth steps are the recruitment and training of participants. The former is usually achieved by participants responding to e.g., newspaper articles and public service announcements and the latter is done by providing participants with project instructions and background material. The sixth step is accepting, editing and displaying the raw data collected by the participant to the public and to the participants themselves. Seventh, the raw data is analyzed and interpreted by the team of experts. Dissemination of the results of the project through publications in scientific journals, technical reports to specific audiences and the projects website is the eight step. And the last step is measuring the whether the project has had the desired effect.

The Danish or democratized version of the Consensus Conference ${ }^{3}$ involves recruiting a group of 10-16 citizens who are selected on the basis several socio-demographic criteria i.e., age, gender, education, occupation, and area of residence (what follows draws on the work of Grundahl, 1995; Andersen and Jæger, 1999). There are two important conditions for being included. First, a would-be participant can have no expert knowledge about the issue. And second, participants can not have any special interest in the case under consideration, e.g., be an interest group representative. The nominated group of citizens is provided with information about the topic of the consensus conference and is tasked with formulating the question that

\footnotetext{
${ }^{2}$ We employ this rather narrow definition of Citizens Science, i.e., as a distribution of cognitive labor, because this seems to be the dominant interpretation of it made by scholars conducting the projects.

However, as a reviewer pointed out to us, a broader interpretation of the terms has been offered by Irwin (1995) who, roughly, understands it as a point of exchange of different forms of knowledge and expertise rather than merely a distribution of cognitive labor.

${ }^{3}$ As opposed to the version used in the United States by the National Institute of Health which includes only medical experts tasked with the assessment of medical technologies (Grundahl, 1995).
}

is to be addressed at the conference. In addition, the citizen group has a decisive influence on the selection of experts that is invited to testify before the group. After the conference, the group issues a public report stating their conception of what the knowns and unknowns of the area under consideration are, as well as the general principles they recommend for policy-making. The preparatory stage, in which participants receive education pertaining to the subject and formulate the central questions usually requires 4 weekends, while the consensus conference itself spans over 3-4 days.

In this section we have described two paradigms of science communication found in the science communication literature, the dissemination paradigm and the public participation paradigm, focusing on the modes of communication and outlets licensed by them. In the next section, we turn to our proposal for how the aims of science communication efforts can be more clearly conceptualized.

\section{A CONCEPTUAL FRAMEWORK OF SCIENCE COMMUNICATION AIMS}

Note some caveats. First, we are not claiming that our conceptual framework exhausts all goals that might be set for science communication efforts. Instead, we modestly argue that the aims reviewed and analyzed below represent some of the most common, although sometimes not fully articulated, aims. Second, some of the aims analyzed below are causally related, that is, sometimes a communicative effort might be directed at one aim in order to achieve some other aim. In the analysis we have noted some of the most common views on causal relations between aims, but we do not claim to have exhausted all ways that communicative aims might be causally related. Third, and related to the former point, we recognize that in practice communicative efforts are sometimes designed with the intention of achieving multiple aims, and that these aims will often be overlapping. However, in order to achieve a greater level of analytical clarity we shall discuss each of the identified aims individually.

We submit that the following largely conceptually distinct aims of communicative efforts can be located in the literature:

(1) Improving the population's beliefs about science.

Improving the population's belief ${ }^{4}$ about science encompasses achieving an increase in the number of people who hold accurate beliefs about new scientific findings, scientific facts, scientific methods, what possibilities and limitations science is subject to, what the risk associated with scientific endeavors are, etc. As might be clear, setting as an aim the improvement of the population's beliefs about science can involve attempting to reach several different (sub)aims such as e.g., reducing the number of false beliefs, increasing the number of true beliefs and increasing the number of people who have correct beliefs, or one can aim for specific distributions of these improvements. Historically, the motivation behind this aim was that

\footnotetext{
${ }^{4} \mathrm{We}$ here intend the term belief to be understood in its standard philosophical meaning which denotes the stance one takes toward something if one regards it as true.
} 
nation-wide surveys from several countries revealed that the majority of the public lack basic knowledge of scientific facts, scientific processes, as well as knowledge about implications of science for society and individuals. Or, in the terminology often employed by scholars drawing conclusions from such studies, the majority of the public was found to be scientifically illiterate (Durant et al., 1989; Miller, 1998, 2016). To mention just a few examples of basic scientific facts that the majority of the public was found to be ignorant of the 1988 The National Science Foundation's Science and Engineering Indicators showed that only $46 \%$ of Americans knew that the earth travels around the sun in a year. And in the most recent from 2018 only $48 \%$ percent knew that electrons are smaller than atoms (National Science Board, 2018). While improving the belief states in the population has been conceived of as an end to pursue in itself (see e.g., The Royal Society, 1985), it is more often mentioned in the literature as being an essential causal factor that promotes other aims of science communication, the most prominent being the claim that it is necessary (or even sufficient) for the generation of pro-science-attitudes in the population [see (2)]. Another prominent view is that improving the beliefs in (at least part of) the population is necessary for the enhancement of democratic legitimacy [see (8)]. The aim of improving beliefs about science might, however, in some cases turn out to work against other aims. For instance, and as will be discussed more at length in section Do Various Models of Science Communication Achieve the Aims? empirical studies have shown that improving the belief states in the population sometimes causes people to have more negative attitudes toward science.

(2) Generating social acceptance.

The aim of generating social acceptance of science as a whole or a certain part of science entails attempting to achieve a distribution of certain kinds of pro-attitudes in the population to funding, governance, and application of science. As already noted, this aim is sometimes assumed to be a likely consequence of improving the belief states of the population (The Royal Society, 1985). More precisely, the lack of understanding of science is said to be seen by some members of the scientific community and policymakers to be the explanation for why the institutions of science are experiencing a lack of public and material support (Bauer, 2009; Brossard and Lewenstein, 2010). The lack of understanding of science is also taken to explain why presenting evidence of scientific consensus about an issue subject to controversy in the public, e.g., that climate change is anthropogenic or the risk associated with employing novel technologies, is often not sufficient to quiet public criticism (stated but not endorsed by Kahan, 2015, 2017). The underlying assumption is that if the knowledge deficit is addressed then one will simultaneously succeed in amending the attitude deficit toward science [sometimes expressed by the axiom "the more you know, the more you will love it" (Bauer et al., 2007)].

Interestingly, however, Burns et al. (2003) have suggested that "a change of attitude toward science [...] may at some later time lead to enhanced scientific literacy" (p. 192). According to these authors the causal relationship between these two aims is thus sometimes reversed, and generating social acceptance of science might be necessary for improving the belief states in the population.

(3) Generating public epistemic and moral trust.

In the often mentioned House of Lords report "Science and Society" of 2000 (House of Lords, 2000) an important rationale behind the lordships' call for an enhanced focus on science communication was to attempt to dissolve what they termed a "crisis of trust" (Durant, 1999; Miller, 2001; Wynne, 2006; see also Dietz, 2013). "Trust" is, of course, an ambiguous term which can refer to at least two different kinds of attitudes and consequently generate two distinct, but in practice often overlapping, aims of science communication. It is useful here to distinguish between epistemic trust and moral trust (for a similar distinction see e.g., Borchelt, 2008; Earle, 2010; Fiske and Dupree, 2014; Myers et al., 2017).

As we understand it, an individual has epistemic trust in a scientific institution when the individual is strongly inclined to believe that what the institution communicates as true and epistemically justified, unless the individual is exposed to salient defeaters, that is, specific reasons to or evidence suggesting that institution in question is not trustworthy. There is public epistemic trust in a scientific institution when most people in a polity, tend to believe what it communicates, again short of defeaters. The science communication aim of promoting public epistemic trust is the aim of bringing about that the communicative efforts emanating from scientific institutions is generally believed by the citizenry, e.g., concerning scientific findings, limitations or potentials of research undertaken, that the scientists working on the research are competent and have the necessary expertise, etc. By contrast, an individual has moral trust in some scientific institution when the individual is inclined to believe that the institution is behaving in a morally proper manner, even when one has no specific information about this.

As others have noted, generating moral trust has received considerably less attention than its epistemic counterpart (Weigold, 2001; Bauer et al., 2007). However, the positive value of generating the confidence among the public that scientific institutions (or the scientists working in said institution) are acting in a morally proper way has recently caught the attention of some scholars, albeit they often employ a different terminology (Borchelt, 2008; Earle, $2010)^{5}$. From a conceptual point of view, there seems to be reason to believe that this aim is causally connected to aim (1) and (2). If, for instance, the public lacks epistemic trust in an institution then the public's beliefs will likely not be improved when receiving scientific information from this institution. In the same vein, if there is a lack of public moral

${ }^{5}$ Earle (2010) employs the term relational trust to denote the kind of trust concerned with the intentions of others, and Borchelt (2008) includes both the integrity and dependability of scientic institutions and scientists to be important components of trust. 
trust in an institution this will likely mean that what the institution communicates will not be socially accepted.

(4) Collect citizens' input about acceptable/worthwhile research aims and applications of science.

Collecting citizens' views on what research aims and applications of science should be pursued is another aim often stressed by scholars and practitioners of science communication. One important motivation underlying this aim is the view that scientific experts often have too narrow a view vis-à-vis citizens' of what social and ethical concerns scientific research or application might give rise to (Andersen and Jæger, 1999; House of Lords, 2000; Jackson et al., 2005). As Andersen and Jæger (1999) explains, an important reason for involving citizens in consensus conferences is that " $\mathrm{t}]$ hey tend to see it [i.e., science and technology] from the perspective of their own life: how could this possibly affect my work situation, my health and the life of my family?" (p. 334). Thus, when aiming to collect citizens' views, the hope is to broaden the scope of concerns considered when e.g., funding decisions are made or when policy decisions regarding the regulation of science are decided. Wynne (2006) has suggested that pursuing this aim of science communication is also likely to contribute to generating trust in science and scientific endeavors [see (3)], and it might be speculated that this aim might also be instrumental in generating social acceptance [see (2)].

(5) Generating political support for science.

The aim of generating political support for science can be understood as promoting a favorable distribution of pro-attitudes toward science among policy-makers, organizations and/or institutions that may have an impact on the funding, governance and application of science. This aim can be usefully compared to the aim reviewed above concerning the collection of the public's input about acceptable/worthwhile research aims and applications of science. If one adopts the latter aim it suffices for the success of one's communicative effort that the public's input is somehow made available to decision-makers and others. However, the aim we are considering here stresses that only when the communicative effort succeeds in attaining a favorable distribution of pro-attitudes among decisionmakers, expressed by e.g., enactment of a recommended policy or funding of a particular part of scientific research, should it be considered reached (see e.g., Fiorino, 1990; Rowe and Frewer, 2000). As Rowe and Frewer (2000) puts it in the context of evaluating the effectiveness of public participating methods " $[t]$ he output of the procedure should have a genuine impact on policy and be seen to do so" (p. 14). This aim is sometimes pursued not only for its own sake, but also because it is believed to be an important part of enhancing the democratic legitimacy of policy decisions regarding science [see (8)] (see e.g., Russell, 2013).

(6) Collect and make use of local knowledge.

Collecting and making use of knowledge located in different parts of the public is another aim found in the literature (see e.g., Jasanoff, 1997; Jackson et al., 2005). Roughly, the idea is that citizens sometimes have local knowledge, that may act as important correctives to scientific views. In Fiorino's words, members of the public may have insights about "problems, issues and solutions that experts miss" (Fiorino, 1990 , p. 227). One proponent of this aim has for example described how local knowledge held by sheepherders in northwest England would have saved the scientists from designing their studies in a way that ultimately confounded their experiments, had the knowledge of sheepherders not been ignored by the scientists (Wynne, 1998; see also Irwin, 1995). One central concern that setting the collection and employment of local knowledge as the aim of science communication is thought to address is thus to improve the quality of scientific knowledge as well as activities informed by science. Another more recent example is the efforts to incorporate patients' knowledge in healthcare settings in terms of e.g., in reaching a correct diagnosis, choosing an appropriate treatment scheme, identifying side-effects of it and how to address them (Ocloo and Matthews, 2016). And patients' knowledge about their local community is sometimes employed to design research protocols sensitive to the social stigma that may accompany certain conditions, as well as more generally aiding scientists in formulating question in a way that is acceptable to a given local community (Brett et al., 2012). It often seems implicitly assumed that if scientific views are infused with layknowledge this might lead to increased trust [see (3)] and/or promote social acceptance of science [see (2)] (see e.g., Jasanoff, 1997).

(7) Make use of distributed knowledge or cognitive resources to be found in the citizenry.

Another aim for some models of science communication is to make use of distributed knowledge or cognitive resources found among citizens. Notice that this aim is different from the aims of collecting and make use of public knowledge (6) as well as the aim of receiving input from the public on worthwhile research aims (4), as the focus for the aim under consideration is to have citizens contribute to the investigation of a question of scientific or social relevance. Put it in formal terms, there is no necessary connection between aim (4) or (6) and the present aim. One could, for instance, pursue either of the latter aims without involving the citizenry in the scientific investigation. And, conversely, it seems possible that the citizenry can be directly involved in a scientific investigation in which the knowledge held by the citizenry is not considered and in which no input is received concerning the desirability of the research aims. One way that this aim is cashed out is by having citizens act as informants on, for example, the state of the local wildlife (Bonney et al., 2009) and their own or others' health condition (Bonney et al., 2014). Another example is crowdsourcing-science games that have participants aiding in deciphering scientific puzzles, such as the structure of and interaction between proteins, through online games. 
It is often argued that making use of the citizenry in these fashions can aid in improving beliefs about science held by (a part of) the population [see (1)].

(8) Enhance the democratic legitimacy of funding, governance and application of science or specific segments of science. The final aim of science communication identified in the literature is that of enhancing the democratic legitimacy of decisions regarding funding, governance, and application of science or specific parts of science. Broadly speaking democratic legitimacy requires that decisions made in political institutions are morally acceptable or justifiable in terms of democratic values (Peter, 2017). Democratic legitimacy is thus different from social acceptance and political support (as we use the term). Democratic legitimacy of science thus concerns a distinct normative property of democratic decisions regarding funding, governance and application of science or specific segments of science. Furthermore, because it seems that several additional requirements must be met by a communicative effort in order for it to qualify as an enhancement of democratic legitimacy, this aim is not reducible to the aim of generating political support for science. That is, achieving this latter aim is often not considered sufficient for having achieved the aim under consideration.

Andersen and Jæger (1999) argue that an important reason why Consensus Conferences should be used is that "in a democratic society citizens are supposed to have the opportunity to influence important decisions affecting their lives" (p. 334). More generally, proponents of this aim assume that the democratic legitimacy of the policy decisions regarding science require, or is at any rate enhanced, if these decisions have been subjected to designated deliberative processes that are employed in addition to the ordinary democratic and deliberative processes (see e.g., Andersen and Jæger, 1999; Einsiedel and Eastlick, 2000; Einsiedel, 2008; O’Doherty and Burgess, 2009; Russell, 2013).

However, little agreement exists among scholars regarding the requirements that the deliberative processes should fulfill in order to promote democratic legitimacy. Proposals that seem to have gained at least some support include securing the representativeness of the lay-public that participates in the deliberative process, ensuring that the deliberative process is transparent for the participant as well as the wider public, ensuring that the participants have access to relevant information, and making sure that the policy recommendations arising from the deliberations generate a response from policymakers (Einsiedel and Eastlick, 2000; Rowe and Frewer, 2000; Hamlett, 2003). In addition, some scholars argue that it should also be ensured that participants involved in the deliberative processes are in fact deliberating and not engaging in some other form of conversation (Cobb, 2013; O'Doherty, 2013). While it is often only mentioned in passing, it is often assumed that a casual relation exists between the aim of promoting democratic legitimacy and the aims of generating social acceptance [see (2)] and trust [see (3)].

\section{DO VARIOUS MODELS OF SCIENCE COMMUNICATION ACHIEVE THE AIMS?}

In section A Conceptual Framework of Science Communication Aims, we identified and analyzed several conceptually distinct aims that have explicitly or implicitly been guiding science communication efforts or which have been argued to do so by other theorists. In this section, we examine the evidence concerning the ability of communication efforts to reach their aims. As briefly mentioned above, some aims are more emphasized by the dissemination paradigm, some more by the public participation paradigm, while others are common ground.

(1) Improving the population's beliefs about science.

Improving the belief states in the population is one of the main aims of the dissemination paradigm (Brossard and Lewenstein, 2010). Is there any empirical evidence that the proposed methods of linear transmission of information from the scientific experts to the public, either through education in a formal school setting or informal education through e.g., the media, has achieved this aim? One way to answer this question would be to focus on the development of the level of civic scientific literacy in countries that have employed these methods. One such country is the United States in which efforts have been made to reduce the "gap of knowledge" about science through formal education. For instance, the US remains one of few countries that requires all college students to take at least a year of science as part of their education (Miller, 2010). Summarizing the last thirty-some years of the findings from measurements of the US population's civic science literacy, Miller has recently noted that:

During the last decade, the proportion of American adults who qualify as being scientifically literate remained at about $28 \%$. Prior to 2007, national surveys had shown a steady increase from approximately $10 \%$ in 1988 to $28 \%$ in 2008 (Miller, 2016, p. 4).

So, while the period from 1988 to 2008 showed an improvement of the belief states in the population, no improvement has been recorded for the period from 2008 to 2016. Miller speculates that the observed increase in the proportion of scientifically literate adults seen in former period, as well as the plateauing observed in the latter period, is partly a function of the level of completed of college-level science courses and bachelor degrees (which presumably showed an increased in the former period but not in the latter period). However, Miller himself acknowledges that more work is needed to establish that his speculations are more than just that (Miller, 2010, 2016).

Several potential sources for informal science education of the public exists, and we cannot here examine them all. Instead we shall examine the known effect of one such source, the mass media e.g., television, science magazines, 
the internet, etc. The question is whether there is empirical evidence supporting the view that they succeed in improving the belief states of the population. Depending on whether studies focus on the short-term or long-term cognitive media effects one seems to get different answers to this question. For instance, when investigating the former Miller et al. (2006) found that a considerable portion of American adults who had watched one or more local news shows containing science and health stories showed "substantial story recall and information retention" (p. 216) in the weeks after the shows had aired. However, if one turns to studies of the media's long-term effect on knowledge levels, the effect becomes less clear. While some doubt that there is such a connection (see e.g., Ten Eyck, 2005) other studies have shown that the mass media does indeed seem to have some long-term influence on the public level of knowledge about biotechnologies (Bauer, 2002; Bonfadelli, 2017) and global warming (Kahlor and Rosenthal, 2009).

While most models belonging to the public participation paradigm often do not state it as a weighty aim to improve the belief states of the population per se, models such as e.g., the Consensus Conference and the Deliberative Opinion Poll, go to great lengths to ensure that its participants are well-informed about competing arguments and relevant scientific facts about the issue under consideration. In fact, the inventor of the Deliberative Opinion Poll, James Fishkin, has recently stated that after every Deliberative Poll he and his team have conducted, there has been a considerable increase in the level of knowledge that the participants have about the issue under consideration compared to control groups (Fishkin, 2009). Another example is Citizen Science projects, which often have as one of their explicit aims to educate their participants about scientific facts and methods. And while it is stressed by scholars that more work is necessary to understand and harness the full potential of Citizen Science projects as educational efforts, studies have shown promising results in terms of heightening the level of domain specific scientific knowledge among the participants (Bonney et al., 2009; Crall et al., 2013). So, insofar as it ever becomes feasible to employ these activities on a greater scale, they might well aid in improving the wider publics beliefs.

(2) Generating social acceptance.

Generating pro-attitudes toward science is another aim often emphasized in the dissemination paradigm. Indeed, one of the main reasons for improving the belief states in the population seems to be the idea that this would lead to more favorable public attitudes toward science. However, the exact nature of the relationship between knowledge about and attitudes toward science has proved to be complex. For instance, in an influential study Evans and Durant (1995) conducted an analysis of a sample of around 2000 British respondents' understanding of and attitudes toward science. On this basis they concluded that they had,
"[...] discovered some evidence that higher levels of knowledge are indeed associated with more supportive attitudes toward science. This appears to hold both for science in general and for what we have termed 'useful science' [i.e., areas of research that are considered socially relevant e.g., cancer research and nuclear energy]. In morally contentious and non-useful areas of research, however, the well informed are more strongly opposed to funding than are the less well informed" (p. 70).

So, while the authors had indeed demonstrated there to be a connection between knowledge of and attitudes toward science, these findings also question whether promoting the public's understanding of science would, as some science communicators and scientists hope, result in more public support for science. Other studies have largely confirmed this conclusion (Durant et al., 1989; Sturgis and Allum, 2004; Allum et al., 2008). What these studies seem to indicate is that one could rely on models in the dissemination paradigm if one wished to cultivate positive attitudes toward science in general or in non-contentious areas of science such as e.g., cancer research. But that mere linear dissemination of scientific information does not generate pro-attitudes, and might even be counterproductive (that is, generate negative attitudes), when it comes to research deemed non-useful (e.g., astronomy) or morally controversial (e.g., stem cell research or global warming). As one might expect, this phenomenon has attracted much attention from scholars and we cannot here engage in a comprehensive review of the studies conducted to explain, counteract or circumvent the negative effect that increased levels of knowledge can have on individuals' attitudes toward certain areas of science (for an excellent overview, see Akin and Scheufele, 2017). In the context of the present discussion, it will suffice to say that the question of how one can generate social acceptance toward science remains an open and highly complex one.

(3) Generation of public epistemic and moral trust.

While numerous studies have been conducted to assess the public's levels of epistemic and moral trust in science in general (e.g., Besley, 2014), and regarding specific areas of research and scientists and scientific institutions (e.g., Myers et al., 2017), the question of what factors mediate and promote trust is just beginning to be uncovered (e.g., Nisbet and Scheufele, 2009; Fiske and Dupree, 2014; Nadelson et al., 2014; Hendriks et al., 2016c; Myers et al., 2017). Consequently, despite the aim of promoting epistemic and moral trust arguably being widely endorsed in the public participation paradigm (see e.g., Dietz, 2013), the research on whether communicative efforts are in fact promoting these aims is limited. However, a recent study (Hendriks et al., 2016a) found that the readers of an article on a science blog (an outlet licensed by the dissemination paradigm) ascribed a considerably higher level of what they termed the integrity 
and benevolence dimensions of trust (which is roughly similar to what we have here termed moral trust) when the scientist who had authored the article disclosed a flaw in the study herself (as opposed to another scientist doing so) (see also Jensen, 2008 for similar findings). However, the study also found that when the scientist disclosed the flaw herself there was a considerable drop in what they termed the expertise dimension of trust (roughly equivalent to what we have termed epistemic trust), indicating that communicative efforts aiming at enhancing public moral trust can have a negative influence on the public's level of epistemic trust. A similar study the same authors (Hendriks et al., 2016b) found that including a discussion of the possible ethical implications of scientific findings (in this case, the potential moral problems with the use of cognitive enhancers) in a blogpost had an noticeable positive impact on the perceived moral trustworthiness of the scientist doing the blogging. They also found that if the ethical aspects where introduced by the author himself, the participants ascribed him more moral trust than when they were introduced by another expert. The authors took this to indicate that scientist who blogs about science "should not shy away from also discussing the implications or applications of scientific results, even if this discussion might raise ethical concerns" (p. 1004). Taken together these studies indicate that it might be possible to employ models belonging to the dissemination paradigm in order to generate public moral and epistemic trust, although more research is surely needed.

Surprisingly, it seems that virtually no work has been done to assess whether models in the public participation paradigm succeed in generating moral and epistemic trust, although this is an often-stressed aim. Perhaps one reasons for this shortcoming in the science communication literature in general is due to a defective approach to trust measurement similar to the one identified by Boschetti et al., when attempting to identify empirical guidelines for building trust among stakeholders in the context of environmental sustainability projects. As they note:

rust is rarely measured [...] as a goal of itself and even more rarely is this done before, during and after a project. As a result, it is difficult to objectively evaluate its contribution to project success or impact. In the literature, it is frequently assumed that trust and engagement are a welcome byproduct of the main research activities if effective outcomes are achieved. The opposite is often also assumed to be true ('Engagement failed; it shows that the team did not build trust'). In other words, often trust is 'deduced' from the outcome of the project itself, with no actual measurement of trust (Boschetti et al., 2016, p. 855f, references omitted).

We do not doubt that there are exceptions to this commonsensical (and tautological) approach to trustbuilding and measurement described here. However, it seems that in the majority of science communication initiatives within the public participation paradigm only few efforts to measure the epistemic or moral trust are being attempted.

(4) Collect and make use of the publics input about acceptable/worthwhile research aims and applications of science.

Due to this particular aim of science communication requiring multiway communication to be reached, it is emphasized almost exclusively by the public participation paradigm. As noted, many models in this paradigm involve the participants pronouncing their considered views on what aspects of the development or use of science should be considered by decision-makers and sometimes what they believe to be the preferable course of action (see e.g., Andersen and Jæger, 1999). Often this statement is made through a written statement or a popular vote (or both) which is then presented to the relevant decision-makers. Some of the models are even designed to ensure that relevant decision-makers are obligated to respond to the announcement. In this sense, at least, it seems that most of the models do indeed achieve this goal, although it often remains unclear what, if any, impact these processes have on actual decisions made by decision-makers.

(5) Generating political support for science.

Recall that proponents of this aim argue that we should only consider communicative efforts successful with respect to this aim if they attain a favorable distribution of pro-attitudes among decision-makers that makes an actual difference, say in the enactment of a recommended policy. The number of studies of this form of impact is scarce and mainly concerns models belonging to the public participation paradigm. For instance, an often cited example of such influence is the 1989 Danish Board of Technology consensus conference on the mapping on the human genome, which resulted in legal regulations that banned companies' from obtaining DNA health profiles from their current and potential employees (Joss, 1998; Andersen and Jæger, 1999) ${ }^{6}$. Another approach that has demonstrated the ability to effect policy issues is the Deliberative Opinion Poll. In China, for instance, the use of it resulted in the reprioritization of government resources from infrastructure to other more basic necessities, e.g., sewage treatment (He and Warren, 2011; Gastil, 2017), and the South Korean government has recently employed and followed the outcome of one regarding the question of whether to expand the countries number of nuclear powerplants (Chung, 2018).

(6) Collect and make use of local knowledge.

Collecting and making use of local knowledge is an aim emphasized most by models under the public participation paradigm. While it seems that evaluations of this particular aim are generally scarce, there has been some studies, mostly in the field of environmental management and

\footnotetext{
${ }^{6}$ For a list of other instances and non-instances of political impact of Consensus
} Conferences in Denmark see Klüver (1995, p. 44). 
public and patient involvement, attempting to answer the question of whether local knowledge is collected and used to correct or inform scientific views. For example, Beierle (2002) reviewed 239 published case studies of diverse forms of stakeholder involvement through e.g., public hearings, workshops, citizen juries, etc. in environmental decisionmaking. He found, among other things, that in the majority of the cases lay participants were indeed "adding new information, ideas and analysis" (p. 739) which sometimes led to the correction of experts assessments [see also Reed (2008) for an overview of similar studies]. And, as already mentioned above, some studies have employed knowledge of local communities provided by patients in the design of research protocols (Brett et al., 2012). So, even though the evaluative data pertaining to this aim is limited, there seems to be reason for optimism among proponents of it.

(7) Make use of distributed resources to be found in the citizenry.

Making use of distributed resources found among the citizenry is an aim pursued by at least two of the models belonging to the public participation paradigm, namely, Citizen Science projects and public and patient involvement. And some projects seem fairly successful in achieving this aim. For instance, the Citizen Science project eBird, a project using an online checklist to have participants aid in "documenting the presence or absence of all species of North American birds in all locations at all times of year" (Bonney et al., 2009, p. 978), receive more than five million observations made by citizens every month. And this data that has been employed in more 90 peer-reviewed articles and books (Bonney et al., 2014). Another example is the online-platform Zooniverse that, according to its website, have over a million members who together have collected hundreds of millions of classifications of, to name just a few projects, animals in the Serengeti, the sex of beluga whales, new exoplanets and solar storms ${ }^{7}$ As is the case with eBird, the data collected through Zooniverse projects has been used in several scientific articles and books. Examples of public patient involvement that seem to achieve this aim, are studies in which the patients interview other patients for research purposes (Elliott et al., 2002; Godfrey, 2004).

(8) Enhance democratic legitimacy of funding, governance and application of science or specific segments of science.

Enhancing democratic legitimacy is an aim emphasized almost exclusively by scholars writing about models of science communication in the public participation paradigm, and practitioners employing those models. Is there any empirical evidence that communicative efforts such as the consensus conference or citizens' juries do indeed enhance democratic legitimacy of policy decisions regarding funding, governance and application of science? Empirical research on this question is faced by two interrelated challenges. First, recall, that the idea is that

${ }^{7}$ https://www.zooniverse.org/ democratic legitimacy is enhanced when specific deliberative processes meeting special criteria are conducted in the right way. Although scholars have made some suggestions regarding what conditions should met in order for the special deliberative processes to be considered properly conducted (and thus act as a enhancer of democratic legitimacy), it remains an underexplored area in the science communication literature (Abels, 2007). Second, and perhaps more importantly, even if scholars are able to identify such conditions, questions pertaining how to evaluate whether they have been met immediately arise. For instance, in order to evaluate a condition stating that participants should be deliberating during the course of the process (a condition often endorsed by proponents of this aim) one needs fairly clear criteria for when something is to count as deliberation, we need a method to investigate empirically whether it occurs during the deliberative processes. The same challenge of course arises for other conditions believed to be necessary for the properly conducted special deliberative processes. In sum, it seems that the normative as well as the empirical framework for evaluating whether the employment of the special deliberative processes is indeed enhancing democratic legitimacy is yet to be developed fully. Consequently, it is currently not possible to confirm or disconfirm empirically whether these processes are indeed achieving their aim.

\section{CONCLUDING REMARKS}

The aim of this paper has been to take the initial steps toward developing a taxonomy of aims of science communication efforts and subsequently surveying the empirical literature to investigate whether these aims are reached in practice. That is, we have attempted to answer the questions also posed in the title of the paper: why engage in science communication, and does it work? To do so, we first identified two very different paradigms of science communication by focusing on the modes of communication licensed by different science communication models. Models belonging to what we termed the dissemination paradigm of science communication employ one-way transmission of scientific information, while the mode of communication licensed by what we termed the public participation paradigm is two- or multi-way communication. We then reviewed the science communication literature focusing on the explicit or implicit aims adhered to by scholars and practitioners, deploying models from the two paradigms and then analyzed these aims using standard concepts from epistemology and political philosophy. We found that using this approach made possible a more fine-grained distinction between the aims and how they may be casually related than is usually found in the science communication literature. With these aims in hand, we then turned to the empirical literature in an attempt to determine whether these aims could be said to have been reached in practice by models belonging to either of the two discerned paradigms. Our main finding is that the literature attempting an empirical evaluation of science communications 
efforts is scarce. While there is a growing bulk of literature focusing on the aim of enhancing social acceptance of science and improvement of beliefs in the population, considerably less work has gone into evaluating other important goals, such as enhancing moral and epistemic trust and democratic legitimacy. We suspect that at least part of the explanation is to be found in the relative lack of conceptual clarity in the explicitly and implicitly stated aims of science communication. Providing a conceptual clear statement of aims of science communication, and how they may interact, might be cumbersome, but is necessary if we wish to move beyond mere conjectures and speculations regarding the success of science communication efforts. It is our hope that the present paper provides a useful starting point for science communicators when formulating their

\section{REFERENCES}

Abels, G. (2007). Citizen involvement in public policy-making: does it improve democratic legitimacy and accountability? The case of pTA. Interdiscipl. Inform. Sci. 13, 103-116. doi: 10.4036/iis.2007.103

Akin, H., and Scheufele, D. A. (2017). "Overview of the science of science communication," in The Oxford Handbook of the Science of Science Communication, eds K. H. Jamieson, D. M. Kahan, and D. A. Scheufele (Oxford: Oxford University Press), 25-33. doi: 10.1093/oxfordhb/9780190497620.013.3

Allum, N., Sturgis, P., Tabourazi, D., and Brunton-Smith, I. (2008). Science knowledge and attitudes across cultures: a meta-analysis. Public Understand. Sci. 17, 35-54. doi: 10.1177/0963662506070159

Andersen, I.-E., and Jæger, B. (1999). Scenario workshops and consensus conferences: towards more democratic decision-making. Sci. Public Policy 26, 331-340. doi: 10.3152/147154399781782301

Andersen, I.-E., and Jæger, B. (2001). Scenario workshops and urban planning in Denmark. PLA Notes 40, 53-56. Available online at: https://pubs.iied.org/pdfs/ G01293.pdf

Bauer, M. W. (2002). Controversial medical and agri-food biotechnology: a cultivation analysis. Public Understand. Sci. 11, 93-111. doi: 10.1088/0963-6625/11/2/301

Bauer, M. W. (2009). The evolution of public understanding of sciencediscourse and comparative evidence. Sci. Technol. Soc. 14, 221-240. doi: $10.1177 / 097172180901400202$

Bauer, M. W., Allum, N., and Miller, S. (2007). What can we learn from 25 years of PUS survey research? Liberating and expanding the agenda. Public Understand. Sci. 16, 79-95. doi: 10.1177/0963662506071287

Beierle, T. C. (2002). The quality of stakeholder-based decisions. Risk Anal. 22,739-749. doi: 10.1111/0272-4332.00065

Besley, J. C. (2014). "Science and technology: Public attitudes and understanding, in Science and Engineering Indicators 2014, ed National Science Board (Arlington VA: National Science Foundation).

Bonfadelli, H. (2017). "Communications about biotechnologies and GMOs across Europe," in The Oxford Handbook of the Science of Science Communication, eds K. H. Jamieson, D. M. Kahan, and D. A. Scheufele (Oxford: Oxford University Press), 157-164. doi: 10.1093/oxfordhb/9780190497620.013.17

Bonney, R., Cooper, C. B., Dickinson, J., Kelling, S., Phillips, T., Rosenberg, K. V., et al. (2009). Citizen science: a developing tool for expanding science knowledge and scientific literacy. Bioscience 59, 977-984. doi: 10.1525/bio.2009.59.11.9

Bonney, R., Shirk, J. L., Phillips, T. B., Wiggins, A., Ballard, H. L., Miller-Rushing, A. J., et al. (2014). Next steps for citizen science. Science 343, 1436-1437. doi: $10.1126 /$ science. 1251554

Borchelt, R. E. (2008). "Public relations in science: managing the trust portfolio," in Handbook of Public Communication of Science and Technology, eds M. Bucchi and B. Trench (New York, NY: Routledge), 147-157.

Boschetti, F., Cvitanovic, C., Fleming, A., and Fulton, E. (2016). A call for empirically based guidelines for building trust among stakeholders communicative aim(s), as well as acting as a reminder of the evaluative challenges science communicators will face in the absence of such work.

\section{AUTHOR CONTRIBUTIONS}

$\mathrm{SH}$ is the first author of the paper, while KK has provided most of the conceptual part of the paper.

\section{FUNDING}

This work was funded by Novo Nordisk Fonden, grant number NNF17SA0031368, and by University of Copenhagen. in environmental sustainability projects. Sustain. Sci. 11, 855-859. doi: $10.1007 /$ s11625-016-0382-4

Brett, J., Staniszewska, S., Mockford, C., Herron-Marx, S., Hughes, J., Tysall, C., et al. (2012). Mapping the impact of patient and public involvement on health and social care research: a systematic review. Health Expect. 17, 637-650. doi: 10.1111/j.1369-7625.2012.00795.x

Brossard, D., and Lewenstein, B. (2010). "A critical appraisal of models of public understanding of science: using practice to inform theory," in Communicating Science - New Agendas in Communication, eds L. Kahlor and P. A. Stout (New York, NY: Routledge), 11-40.

Bubela, T., Nisbet, M. C., Borchelt, R., Brunger, F., Critchley, C., Einsiedel, E., et al. (2009). Science communication reconsidered. Nat. Biotechnol. 27, 514-518. doi: $10.1038 /$ nbt0609-514

Burns, T. W., O'Connor, D. J., and Stocklmayer, S. M. (2003). Science communication - a contemporary definition. Public Understand. Sci. 12, 183-202. doi: $10.1177 / 09636625030122004$

Chung, J.-B. (2018). Let democracy rule nuclear energy. Nature 555:415. doi: $10.1038 / \mathrm{d} 41586-018-03264-8$

Cobb, M. D. (2013). "Deliberative fears: citizens deliberation about science in a national consensus conference," in Public Engagement and Emerging Technologies, eds K. O’Doherty and E. Einsiedel (Vancouver, BC: UBC Press), 115-122.

Correll, J., Spencer, S. J., and Zanna, M. P. (2004). An affirmed self and an open mind: self-affirmation and sensitivity to argument strength. J. Exp. Soc. Psychol. 40, 350-356. doi: 10.1016/j.jesp.2003.07.001

Crall, A. W., Jordan, R., Holfelder, K., Newman, G. J., Graham, J., and Waller, D. M. (2013). The impacts of an invasive species citizen science training program on participant attitudes, behavior, and science literacy. Public Understand. Sci. 22, 745-764. doi: 10.1177/0963662511434894

Dietz, T. (2013). Bringing values and deliberation to science communication. Proc. Natl. Acad. Sci. U.S.A. 110(Suppl. 3), 14081-14087. doi: $10.1073 /$ pnas. 1212740110

Druckman, J. N., and Lupia, A. (2017). "Using frames to make scientific communication more effective," in The Oxford Handbook of the Science of Science Communication, eds K. H. Jamieson, D. M. Kahan, and D. A. Scheufele (Oxford: Oxford University Press), 13-31. doi: 10.1093/oxfordhb/9780190497620.013.38

Durant, J. (1999). Participatory technology assessment and the democratic model of the public understanding of science. Sci. Public Policy 26, 313-319. doi: $10.3152 / 147154399781782329$

Durant, J. R., Evans, G. A., and Thomas, G. P. (1989). The public understanding of science. Nature 340, 11-14. doi: 10.1038/340011a0

Earle, T. C. (2010). Trust in risk management: a model-based review of empirical research. Risk Anal. 30, 541-574. doi: 10.1111/j.1539-6924.2010.01398.x

Einsiedel, E. F. (2008). "Public participation and dialogue," in Handbook of Public Communication of Science and Technology, eds M. Bucchi and B. Trench (New York, NY: Routledge), 173-184. 
Einsiedel, E. F., and Eastlick, D. L. (2000). Consensus conferences as deliberative democracy. Sci. Commun. 21, 323-343. doi: 10.1177/1075547000021 004001

Elliott, E., Watson, A., and Harries, U. (2002). Harnessing expertise: involving peer interviewers in qualitative research with hard-to-reach populations. Health Expect. 5, 172-178. doi: 10.1046/j.1369-6513.2002.00158.x

Evans, G., and Durant, J. (1995). The relationship between knowledge and attitudes in the public understanding of science in Britain. Public Understand. Sci. 4, 57-74. doi: 10.1088/0963-6625/4/1/004

Fiorino, D. J. (1990). Citizen participation and environmental risk: a survey of institutional mechanisms. Sci. Technol. Hum. Values 15, 226-243. doi: $10.1177 / 016224399001500204$

Fishkin, J., Luskin, R., and Jowell, R. (2000). Deliberative polling and public consultation. Parliament. Affairs 53, 657-666. doi: 10.1093/pa/53.4.657

Fishkin, J. S. (2003). Consulting the public through deliberative polling. J. Policy Anal. Manage. 22, 128-133. doi: 10.1002/pam.10101

Fishkin, J. S. (2009). When the People Speak: Deliberative Democracy \& Public Consultation. Oxford: Oxford University Press.

Fiske, S. T., and Dupree, C. (2014). Gaining trust as well as respect in communicating to motivated audiences about science topics. Proc. Natl. Acad. Sci. U.S.A. 111(Suppl. 4), 13593-13597. doi: 10.1073/pnas.1317505111

Gastil, J. (2017). "Designing public deliberation at the intersection of science and public policy," in The Oxford Handbook of the Science of Science Communication, eds K. H. Jamieson, D. M. Kahan, and D. A. Scheufele (Oxford: Oxford University Press), 233-242. doi: 10.1093/oxfordhb/9780190497620.013.26

Gastil, J., and Levine, P. (eds.). (2005). The Deliberative Democracy Handbook: Strategies for Effective Civic Engagement in the 21st Century. San Francisco, CA: Jossey-Bass.

Godfrey, M. (2004). More than 'involvement': how commissioning user interviewers in the research process begins to change the balance of power. Practice 16, 223-231. doi: 10.1080/0950315042000306697

Grundahl, J. (1995). "The Danish consensus conference model," in Public Participation in Science: The Role of Consensus Conferences in Europe, eds S. Joss and J. Durant (London: Science Museum with the support of the European Commission Directorate General XII), 31-40.

Hamlett, P. W. (2003). Technology theory and deliberative democracy. Sci. Technol. Hum. Values 28, 112-140. doi: 10.1177/0162243902238498

He, B., and Warren, M. E. (2011). Authoritarian deliberation: the deliberative turn in Chinese political development. Perspect. Politics 9, 269-289. doi: $10.1017 /$ S1537592711000892

Hendriks, F., Kienhues, D., and Bromme, R. (2016a). Disclose your flaws! Admission positively affects the perceived trustworthiness of an expert science blogger. Stud. Commun. Sci. 16, 124-131. doi: 10.1016/j.scoms.2016. 10.003

Hendriks, F., Kienhues, D., and Bromme, R. (2016b). Evoking vigilance: would you (dis)trust a scientist who discusses ethical implications of research in a science blog? Public Understand. Sci. 25, 992-100. doi: 10.1177/09636625166 46048

Hendriks, F., Kienhues, D., and Bromme, R. (2016c). "Trust in science and the science of trust," in Trust and Communication in a Digitized World: Models and Concepts of Trust Research, ed B. Blöbaum (Cham: Springer International Publishing), 143-159. doi: 10.1007/978-3-319-28059-2_8

Hörning, G. (1999). Citizens' panels as a form of deliberative technology assessment. Sci Public Policy 26, 351-359. doi: 10.3152/147154399781782284

House of Lords (2000). Science and Society Retrieved from: https://publications. parliament.uk/pa/ld199900/ldselect/ldsctech/38/3801.htm

Irwin, A. (1995). Citizens Science: A Study of People, Expertise and Sustanible Development. London: Routhledge.

Jackson, R., Barbagallo, F., and Haste, H. (2005). Strengths of public dialogue on science-related issues. Crit. Rev. Int. Soc. Polit. Philos. 8, 349-358. doi: $10.1080 / 13698230500187227$

Jasanoff, S. (1997). Civilization and madness: the great BSE scare of 1996. Public Understand. Sci. 6, 221-232. doi: 10.1088/0963-6625/6/3/002

Jensen, J. D. (2008). Scientific uncertainty in news coverage of cancer research: effects of hedging on scientists and journalists credibility. Hum. Commun. Res. 34, 347-369. doi: 10.1111/j.1468-2958.2008.00324.x
Joss, S. (1998). Danish consensus conferences as a model of participatory technology assessment: an impact study of consensus conferences on Danish Parliament and Danish public debate. Science Public Policy 25, 2-22.

Kahan, D. (2010). Fixing the communications failure. Nature 463, 296-297. doi: $10.1038 / 463296$ a

Kahan, D. (2015). What is the 'Science of Science Communication'? J. Sci. Commun 14, 1-10. doi: $10.22323 / 2.14030404$

Kahan, D. (2017). "On the sources of ordinary science knowledge and extraordinary science ignorance," in The Oxford Handbook of the Science of Science Communication, eds K. H. Jamieson, D. M. Kahan, and D. A. Scheufele (Oxford: Oxford University Press), 35-49. doi: 10.1093/oxfordhb/9780190497620.013.4

Kahan, D. M., Braman, D., Cohen, G. L., Gastil, J., and Slovic, P. (2010). Who fears the HPV vaccine, who doesn't, and why? an experimental study of the mechanisms of cultural cognition. Law Hum. Behav. 34, 501-516. doi: 10.1007/s10979-009-9201-0

Kahlor, L., and Rosenthal, S. (2009). If we seek, do we learn? Predicting knowledge of global warming. Sci. Commun. 30, 380-414. doi: 10.1177/1075547008328798

Kaplan, M., and Dahlstrom, M. (2017). "How narrative functions in entertainment to communicate science," in The Oxford Hanbook of the Science of Science Communication, eds K. H. Jamieson, D. M. Kahan, and D. A. Scheufele (Oxford: Oxford University Press), 311-319. doi: 10.1093/oxfordhb/9780190497620.013.34

Klüver, L. (1995). "Consensus conferences at the danish board of technology, in Public Participation in Science: The Role of Consensus Conferences In Europe, eds S. Joss and J. Durant (London: Science Museum with the support of the European Commission Directorate General XII), 41-49.

Miller, J. D. (1998). The measurement of civic scientific literacy. Public Understand. Sci. 7, 203-223. doi: 10.1088/0963-6625/7/3/001

Miller, J. D. (2010). "Civic scientific literacy: the role of the media in the elecronic era," in Science and the Media, eds D. Kennedy and G. Overholser (Cambridge, MA: American Academy of Arts and Sciences), 44-63.

Miller, J. D. (2012). What colleges and universities need to do to advance civic scientific literacy and preserve american democracy. Liberal Educ. 98, 28-33. Available online at: https://www.aacu.org/publications-research/periodicals/ what-colleges-and-universities-need-do-advance-civic-scientific

Miller, J. D. (2016). Civic Scientific Literacy in the United States in 2016: A Report Prepared for the National Aeronautics and Space Administration by the University of Michigan. Retrieved from http://home.isr.umich.edu/files/2016/ 10/NASA-CSL-in-2016-Report.pdf

Miller, J. D., Augenbraun, E., Schulhof, J., and Kimmel, L. G. (2006). Adult science learning from local television newscasts. Sci. Commun. 28, 216-242. doi: $10.1177 / 1075547006294461$

Miller, S. (2001). Public understanding of science at the crossroads. Public Understand. Sci. 10, 115-120. doi: 10.1088/0963-6625/10/1/308

Myers, T. A., Kotcher, J., Stenhouse, N., Anderson, A. A., Beall, E. M., and Leiserowitz, A. (2017). Predictors of trust in the general science and climate science research of US federal agencies. Public Understand. Sci. 26, 843-860. doi: 10.1177/0963662516636040

Nadelson, L., Jorcyk, C., Yang, D., Smith, M. J., Matson, S., Cornell, K., et al. (2014). I just don't trust them: the development and validation of an assessment instrument to measure trust in science and scientists. Schl. Sci. Math. 114, 76-86. doi: $10.1111 / \mathrm{ssm} .12051$

National Academies of Sciences, Engineering, and Medicine (2017). Communicating Science Effectively: A Research Agenda (978-0-309-45102-4).

National Science Board (2018). Science and Technology: Public Attitudes and Understanding Science \& Engineering Indicators 2018. Washington DC: U.S. Government Printing Office.

Nisbet, M. C. (2010). "Framing science: a new paradigm in public engagement," in Communicating Science: New Agendas in Communication, eds L. Kahlor and P. A. Stout (New York, NY: Routhledge), 40-67.

Nisbet, M. C., and Scheufele, D. A. (2009). What's next for science communication? Promising directions and lingering distractions. Am. J. Bot. 96, 1767-1778. doi: 10.3732/ajb.0900041

Ocloo, J., and Matthews, R. (2016). From tokenism to empowerment: progressing patient and public involvement in healthcare improvement. BMJ Qual. Saf. 25, 626-632 doi: 10.1136/bmjqs-2015-004839 
O’Doherty, K. (2013). “Theorizing deliberative discourse," in Public Engagement and Emerging Technologies, eds K. O'Doherty and E. Einsiedel (Vancouver, BC: UBC Press), 133-147.

O’Doherty, K. C., and Burgess, M. M. (2009). Engaging the public on biobanks: outcomes of the BC biobank deliberation. Public Health Genomics 12, 203-215. doi: $10.1159 / 000167801$

Peter, F. (2017). "Political legitimacy," in Stanford Encyclopedia of Philosophy, ed E. N. Zalta. Available online at: https://plato.stanford.edu/archives/sum2017/ entries/legitimacy/

Reed, M. S. (2008). Stakeholder participation for environmental management: a literature review. Biol. Conserv. 141, 2417-2431. doi: 10.1016/j.biocon.2008.07.014

Rowe, G., and Frewer, L. J. (2000). Public participation methods: a framework for evaluation. Sci. Technol. Hum. Values 25, 3-29. doi: $10.1177 / 016224390002500101$

Rowe, G., and Frewer, L. J. (2005). A typology of public engagement mechanisms. Sci. Technol. Hum. Values 30, 251-290. doi: 10.1177/0162243904271724

Russell, A. W. (2013). Improving legitimacy in nanotechnology policy development through stakeholder and communityengagement: forging new pathways. Review Policy Res. 30, 566-587. doi: 10.1111/ropr.12037

Sánchez-Mora, M. C. (2016). Towards a taxonomy for public communication of science activities. J. Sci. Commun. 15, 1-8. doi: 10.22323/2.15020401

Smith, G., and Wales, C. (1999). The theory and practice of citizens' juries. Policy Polit. 27, 295-308. doi: 10.1332/030557399782453118

Sturgis, P., and Allum, N. (2004). Science in Society: Re-evaluating the deficit model of public attitudes. Public Understand. Sci. 13, 55-74. doi: $10.1177 / 0963662504042690$

Ten Eyck, T. A. (2005). The media and the public opinion on genetics and biotechnology: mirrors, windows, or walls? Public Understand. Sci. 14, 305-316. doi: $10.1177 / 0963662505052888$

The Royal Society (1985). The Public Understanding of Science. Retrieved from: https://royalsociety.org/\$ $\$$ sim $\$ /$ media/Royal_Society_Content/policy/ publications/1985/10700.pdf
Trench, B. (2008). "Towards an analytical framework of science communication models," in Communicating Science in Social Context, eds D. Cheng, M. Claessens, N. R. J. Gascoigne, J. Metcalfe, B. Schiele, and S. Shi (Springer), 119-135. doi: 10.1007/978-1-4020-8598-7 7

Turner, S. (2008). School science and its controversies; or, whatever happened to scientific literacy? Public Understand. Sci. 17, 55-72. doi: 10.1177/0963662507075649

Wachelder, J. (2003). Democratizing science: various routes and visions of dutch science shops. Sci. Technol. Hum. Values 28, 244-273. doi: 10.1177/0162243902250906

Weigold, M. F. (2001). Communicating Science: a review of the literature. Sci. Commun. 23, 164-1993. doi: 10.1177/10755470010230 02005

Wynne, B. (1998). "May the sheep safely graze? a reflexive view of the expertlay knowledge divide," in Risk, Environment and Modernity: Towards a New Ecology, eds S. Lash, B. Szerszynski, and B. Wynne (London: Sage), 44-83. doi: $10.4135 / 9781446221983 . n 3$

Wynne, B. (2006). Public engagement as a means of restoring public trust in science-hitting the notes, but missing the music? Commun. Genet. 9, 211-220. doi: 10.1159/000092659

Ziman, J. (1991). Public understanding of science. Sci. Technol. Hum. Values 16, 99-105. doi: 10.1177/016224399101600106

Conflict of Interest: The authors declare that the research was conducted in the absence of any commercial or financial relationships that could be construed as a potential conflict of interest.

Copyright $\odot 2019$ Kappel and Holmen. This is an open-access article distributed under the terms of the Creative Commons Attribution License (CC BY). The use, distribution or reproduction in other forums is permitted, provided the original author(s) and the copyright owner(s) are credited and that the original publication in this journal is cited, in accordance with accepted academic practice. No use, distribution or reproduction is permitted which does not comply with these terms. 